\title{
Reestruturação produtiva, terceirização e relações de trabalho na indústria petrolífera offshore da Bacia de Campos (RJ)
}

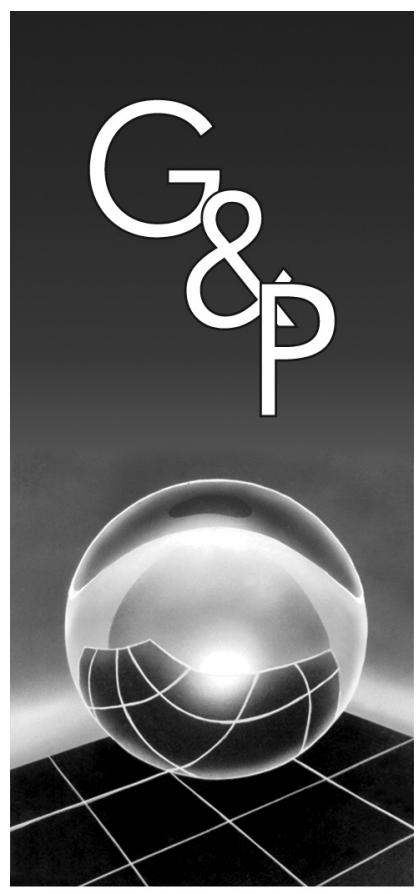

\author{
Marcelo Figueiredo \\ Denise Alvarez \\ Milton Athayde \\ José Diego Suarez \\ Renata Pereira
}

\begin{abstract}
Resumo
Este artigo analisa as correlações do uso intensivo da tercerização com as relações de trabalho nas plataformas offshore da Bacia de Campos (RJ). Abordamos prioritariamente o intervalo que abrange os últimos 10 anos, período em que acompanhamos de forma sistemática o referido campo empírico. O referencial teóricometodológico utilizado no curso da pesquisa, na qual se insere esta contribuição, inspira-se com maior ênfase no instrumental da Ergonomia da Atividade e da Psicodinâmica do Trabalho numa perspectiva ergológica. Em nossa análise, além da tendência à precarização do trabalho em sentido mais global, merecem destaque as possiveis perdas no ativo de conhecimento formal e informal (um patrimônio longamente acumulado) devido à fragmentação dos coletivos de trabalho, já que consideramos a coesão destes um elemento crucial para a confiabilidade do sistema. Em verdade, a precarização do trabalho contribui para esta fragmentação, $e$ tem como uma de suas causas o avanço pouco criterioso da terceirização, na esteira das várias iniciativas de flexibilização organizacional ligadas à reestruturação
\end{abstract} produtiva do setor. Isto acarretou conseqüências nefastas para a saúde e a segurança dos trabalhadores indicando que a opção pela terceirização como instrumento de gestão, da forma com que vinha sendo conduzida até recentemente, não estaria considerando tais implicações com o devido rigor.

Palavras-chave: Terceirização. Reestruturação produtiva. Indústria petrolifera offshore. Sistemas sociotécnicos complexos. Relações de trabalho. Saúde e segurança.

\section{Introdução}

Neste artigo é nossa intenção analisar como a adoção de determinadas formas de gestão - e em particular a ampliação da terceirização, no bojo do processo que ficou conhecido como reestruturação produtiva - contribui para a precarização do trabalho colocando em risco a coesão dos coletivos de trabalho. Na medida em que esta coesão é colocada em xeque, engendram-se elementos desestabilizadores para a confiabilidade no curso do processo de exploração e produção petrolífera offshore na bacia de Campos (RJ) - o qual se insere no rol dos chamados sistemas socitécnicos complexos - ocasionando também efeitos potencialmente nocivos para a saúde e a segurança dos trabalhadores.

A escolha da atividade offshore como nosso campo empírico prioritário se justifica, dentre outras, com base nas seguintes razões: 1) abre espaço para investigar o risco de acidentes ampliados; 2) permite abordar de modo fecundo a dimensão coletiva do trabalho; e 3) envolve a subcontratação de equipamentos e de serviços na indústria do petróleo - com suas várias modalidades de terceirização - assunto que para muitos especialistas mereceria ser investigado mais detidamente. Conquanto a discussão sobre a terceirização ocupe aqui um maior espaço - mais precisamente suas interfaces com a temática das relações de trabalho e dos coletivos de trabalho -, é importante frisar que o desenvolvimento do texto evidenciará a articulação entre os três itens acima.

Cabe mencionar ainda que este artigo é um dos resultados do projeto "Trabalho, saúde e segurança na indústria petrolífera offshore na Bacia de Campos", desenvolvido 
pelo Núcleo de Estudos em Inovação, Conhecimento e Trabalho (Neict/UFF) em parceria com o Sindicato dos Petroleiros do Norte Fluminense (Sindipetro-NF), sediado em Macaé (RJ), e apoiado pela Faperj. O referido projeto se propõe a analisar as condições gerais em que se desenvolve o trabalho dos petroleiros na Bacia de Campos (região norte do Estado do Rio de Janeiro) e suas relações com a saúde e a segurança (FIGUEIREDO et al., 2004).

O referencial teórico-metodológico que norteia a pesquisa que originou a presente contribuição está calcado principalmente na Ergonomia da Atividade e na Psicodinâmica do Trabalho. Cabe salientar, no entanto, que os subsídios vinculados a estas abordagens são enriquecidos, quando necessário, com os aportes de outros referenciais, levando-se em conta a singularidade e as vicissitudes do contexto estudado, demarcando uma perspectiva pluridisciplinar de análise de situações de trabalho, na linha do que propõe a abordagem ergológica (SCHWARTZ, 2000).

\section{Reestruturação produtiva e terceirização na indústria petroquímica}

Cabe frisar, de início, que malgrado a terceirização tenha estado em franca disseminação na Petrobras, até recentemente, ela não configura um fenômeno novo na indústria do petróleo. Pelo contrário, desde as primeiras décadas do século XX engendrou-se em torno das companhias de petróleo uma extensa rede de produtos e serviços oferecidos por terceiros, firmas especializadas que se constituíram para difundir as inovações de seus fundadores, conforme assinala Dutra (1996). Este autor cita três, entre os maiores grupos e os respectivos serviços, que possuem liderança: Halliburton (cimentação), Baker e Hugues (brocas convencionais), Schlumberger (sondagens de poços). As duas primeiras são americanas e a última é uma multinacional francesa. Esses grupos atuam na Bacia de Campos, há pelo menos trinta e cinco anos, e o que se verifica de uns anos para cá é um recrudescimento dessas terceirizações, inclusive em atividades-fim da Petrobras.

Em verdade, tem-se a constituição de um sistema de produção que tanto historicamente como estruturalmente, devido à natureza da atividade, sempre dependeu da formação de uma rede de empresas, atuando da exploração à distribuição. Suas características atuaram como fatores predisponentes para o avanço da terceirização. Dentre elas poderíamos citar: a variedade de tarefas altamente especializadas; a natureza seqüencial e, a curto prazo, de muitas atividades; e a realização de operações em áreas distantes. Um exemplo emblemático desta especialização é o caso das intervenções com mergulho profundo, que será comentado adiante, sucintamente.
Constata-se que as características da atividade petrolífera a inserem no conjunto daquelas que antecipavam a possibilidade de flexibilização do processo ao introduzir-se uma dada inovação tecnológica e/ou organizacional, com incisivas alterações no trabalho dos profissionais envolvidos.

Os arranjos que se configuraram no desenvolvimento desta indústria nos levam a concordar com Dutra (1996) ao enfatizar que a articulação do papel das empresas subcontratadas (terceirizadas) à história do petróleo é um tópico de pesquisa que "merece indiscutivelmente mais atenção". Para o autor, os fornecedores de equipamentos e serviços atuam como uma espécie de quarto agente - além das multinacionais do petróleo, dos países produtores e dos consumidores.

Em seguida, avaliamos ser conveniente proceder a uma breve contextualização a respeito de alguns pontos importantes associados ao avanço da terceirização no bojo da reestruturação produtiva na indústria do petróleo, reproduzindo, neste setor de nossa economia, guardadas as suas devidas especificidades, tendências em curso no cenário internacional de reestruturação do capitalismo e suas manifestações no mundo do trabalho.

Como resposta à crise e ao esgotamento do padrão de desenvolvimento fordista, as empresas ocidentais tentaram incorporar, sob distintas configurações, a partir dos anos 80, algumas das inovações tecnológicas e organizacionais engendradas e difundidas com o avanço do ideário japonês. A implementação deste conjunto de inovações ao longo desse período foi denominada, genericamente, de reestruturação produtiva e, em função do vulto e das implicações associadas, as transformações ainda em curso levaram alguns autores a falar no advento de uma Terceira Revolução Industrial.

É nesse cenário, ainda em fase de consolidação, que emerge o chamado padrão de acumulação flexível, no qual à reestruturação produtiva articulam-se a ascensão das políticas neoliberais e o processo de globalização - ou mundialização como preferem alguns autores, sob hegemonia do capital financeiro (CHESNAIS, 2005). É importante frisar que a esta reestruturação esteve aliada uma substancial aceleração da participação do setor terciário (de serviços) com destaque para o setor dito de “informação" (CASTELLS, 1991). E se, nesta direção, é pertinente sublinhar que no cerne das inovações subjacentes à reestruturação produtiva cresceu a importância da "relação de serviço", não devemos restringi-la ao setor de serviços stricto sensu, mas encará-la, conforme Zarifian (2001), como estando presente em todos os setores do tecido econômico.

A reestruturação produtiva se caracteriza, como dissemos, pela implantação de inovações tecnológicas e organizacionais, no Brasil sobretudo a partir da década de 1980, devendo-se realçar o papel que aí tiveram aquelas 
inovações oriundas do chamado modelo japonês de produção. Nesta direção, a disseminação da terceirização pode ser vista como um dos reflexos da reestruturação da produção presente na transição do padrão de acumulação fordista, para o modelo de acumulação flexível (HARVEY, 1992), ou pós-fordista (LAZZARATO; NEGRI, 2001), que tem como um de seus focos privilegiados dotar o processo produtivo da capacidade de se modular frente às demandas dos clientes e às flutuações do mercado.

Mas tais considerações nos levam ao seguinte questionamento: sabemos que diversas análises acerca dessas mudanças tomam como referência prioritária a indústria de processo discreto ou descontínuo - tendo como paradigma maior a indústria automobilística -, com diferenças essenciais em relação à indústria de processo contínuo, como é o caso da exploração e produção petrolífera offshore. Lembramos que essas e outras nuances fizeram com que se considerasse a petroquímica uma espécie de novo paradigma produtivo. Seria então correto conceber a petroquímica como inserida nos marcos desta transição, do padrão fordista para o padrão de acumulação flexível (pós-fordista)? Em que medida tal enfoque se aplicaria ao contexto estudado?

A despeito de demarcar tais distinções, Druck (1999) identificou na indústria petroquímica baiana traços de um padrão fordista, no que diz respeito à gestão do trabalho. A autora acrescenta que, na segunda metade dos anos 80 , verificou-se uma tendência de queda da produtividade do setor petroquímico num contexto de crise crônica no plano nacional, o que somado às redefinições dos mercados no plano internacional, também impuseram ao setor químico e petroquímico novas condições de competitividade. Era o começo do "novo padrão flexível do mercado de petróleo, a exemplo dos demais mercados" (TORRES FILHO, 2004, p. 343), momento marcado por níveis muito baixos dos preços internacionais.

[...] racionalização das atividades exploratórias e extrativas, difusão de tecnologias redutoras de custos, eliminação dos postos de trabalho nas plantas, embarcações e plataformas e aprofundamento da 'terceirização' foram as palavras de ordem em todas as empresas de petróleo durante a segunda metade da década de 1980. (DUTRA; CECCHI, 1998, p. 120).

Não resta dúvida que tais ditames contribuíram para impulsionar mudanças nas práticas predominantes de gestão do trabalho, ensejando a alteração de rota que Druck (1999) denominou de "desfordização". Portanto, não obstante as distinções a que fizemos menção há pouco, tal processo gestou-se em sintonia com certos princípios de flexibilização que vinham se afirmando na esteira do novo padrão de acumulação flexível (pós-fordista). Uma das estratégias adotadas foi a difusão da implementação das terceirizações e dos programas de qualidade total. No caso estudado por Druck (1999), o recrudescimento da terceirização estaria levando ao aumento da precarização, tendência também identificada em outras realidades e que constatamos na Bacia de Campos, conforme se verá.

De nosso lado, mais do que entrar nas polêmicas que este tipo de debate reacende, buscamos apreender como algumas destas tendências (ao aumento da terceirização, por exemplo), no curso das transformações mais gerais, estariam se manifestando na indústria petroquímica, em particular no setor offshore. Neste movimento, chamamos a atenção para o risco de sucumbirmos à não valorização das singularidades de cada contexto, que podem ser obscurecidas por visões homogeneizadoras. Seria, em nosso entendimento, um grave equívoco, já que em meio às dialéticas entre o local e o global, "o eixo das ressingularizações" nos alerta para a necessidade de reajustarmos permanentemente os aportes intelectuais de análise histórica (SCHWARTZ, 1995).

Uma outra tendência que também foi aprofundada no decorrer da reestruturação produtiva na indústria petroquímica brasileira diz respeito à redução de efetivos. É importante salientar que a terceirização, até certo ponto, articula-se com a redução de efetivos, na medida em que esta última, por diversas vezes, foi acompanhada de uma crescente terceirização de várias atividades operacionais.

Segundo Duarte (1994), não raro, a política de redução de efetivos na indústria petroquímica está calcada numa representação equivocada do trabalho real dos operadores, pois parte de uma premissa que considera a estabilidade e o bom funcionamento os aspectos predominantes no curso do processo. Todavia, o que as análises ergonômicas demonstram é que esses processos são marcados por um alto grau de variabilidade e de incerteza, sobretudo as unidades antigas, nas quais a degradação é um traço frequiente (DUARTE; VIDAL, 2000). Aliás, o caráter aleatório e imprevisível de alguns eventos é uma característica intrínseca aos sistemas tecnológicos complexos com suas interações não-lineares, aquelas que, em geral, não são previstas no projeto original de tais sistemas (PERROW, 1984). Assim, a representação que se tem da frequiência e do conteúdo das intervenções desses operadores no transcorrer do processo não corresponde ao trabalho efetivamente realizado por eles. Em virtude desta distorção, tem havido um subdimensionamento do número de operadores das equipes em seus respectivos turnos, trazendo conseqüências nefastas para a segurança.

Em suma, deve-se frisar que no setor petrolífero a reestruturação produtiva também aparece como uma resposta à necessidade de maior produtividade e maior flexibilidade, perpetrando neste setor alterações substantivas na gestão do trabalho, seguindo a tendência predominante 
em outros contextos industriais. A focalização das atividades core da empresa e ações no âmbito da desregulação do trabalho visam a atender a uma demanda crescente por maior lucratividade nesse setor. Dessa forma, ganhou enorme espaço a opção pela terceirização, tendo como justificativa principal, por parte da empresa, a necessidade desta se deter às suas atividades-fim e repassar a terceiros aquilo que não está no seu escopo principal (as atividades-meio).

Cabe ressaltar ainda que no cenário brasileiro, em termos tendenciais predominantes, a precarização e o desemprego parecem ser os custos maiores da flexibilização nos anos 90, juntamente com a debilitação da capacidade de mobilização e reivindicação dos trabalhadores. No contexto da petroquímica, Druck (1999) afirma que os achados empíricos de sua pesquisa ligada ao Complexo Petroquímico de Camaçari demonstraram que a terceirização teria levado a uma quádrupla precarização: do trabalho, da saúde dos trabalhadores, do emprego e das ações coletivas. No Brasil, outros estudos realizados nesse setor, em estágios variados de aprofundamento, demonstraram que, no bojo do processo de reestruturação produtiva na petroquímica, o aumento da terceirização e a redução de efetivos - e, em sentido mais amplo, as mudanças de cunho organizacional -, sobretudo em algumas etapas-chave do processo como a manutenção, podem ter implicações sérias sobre a saúde e a segurança dos trabalhadores e a confiabilidade do sistema (DUARTE, 1994; FERREIRA; IGUTI, 1996; SEVÁ FILHO, 1997; MACHADO et al., 2000; ARAÚJO, 2001; FIGUEIREDO, 2001). A ergonomia da atividade, e os princípios fundamentais que a norteiam (DANIELLOU, 2004), pode ser vista como um eixo comum de tais estudos, que em graus diferenciados tiveram como referências importantes, para avançar no debate sobre o trabalho em sistemas complexos, as contribuições de Leplat e Terssac (1990), Daniellou (1992) e, especialmente, Wisner (1994).

\section{A terceirização e os coletivos de trabalho na indústria petroquímica}

A indústria petrolífera offshore pode ser caracterizada como um sistema sociotécnico complexo. Sociotécnico, porque resulta da interação de um conjunto de indivíduos e instrumentos técnicos com os quais estes indivíduos estão incumbidos de realizar uma missão (LEPLAT; TERSSAC, 1990). Complexo, porque nas indústrias de processo, como a petroquímica, predominam as chamadas interações não-lineares, cuja complexidade deve-se à possibilidade de multiplicarem-se os eventos à medida que outras partes ou subsistemas são atingidos (PERROW, 1984). Também são tidos como fontes de complexidade o risco, vinculado à instabilidade do sistema, e a neces- sidade de cooperação entre seus agentes. Portanto, nessa indústria, em que há inúmeras conexões e os componentes estão intimamente acoplados, os casos de falhas podem acarretar acidentes graves devido à imprevisibilidade das múltiplas interações que venham a se estabelecer, tal como abordamos em Figueiredo (2001). O debate no que tange aos coletivos de trabalho, apenas esboçado sucintamente neste tópico, foi desenvolvido de modo mais extenso em Figueiredo e Athayde (2004).

Considerando os elementos apontados acima, podemos afirmar que a dimensão coletiva é um aspecto marcante na confiabilidade do sistema. Segundo Leplat e Terssac (1990), "[...] a eficácia e a confiabilidade dos sistemas sociotécnicos complexos apoiariam-se na cooperação e no coletivo de trabalho".

Com efeito, os coletivos de trabalho pressupõem a existência de regras e leis que transcendem a esfera da hierarquia. Estas ajudam a organizar as relações entre os trabalhadores, dando coesão ao coletivo que, por sua vez, protege as regras de ameaças externas, buscando adaptálas diante das inovações tecnológicas e organizacionais em curso. Os modelos de organização do trabalho que, de alguma forma, criam obstáculos e promovem seu desmonte, estariam minando o potencial de cooperação aí existente (DEJOURS, 1997).

Nesse contexto, indubitavelmente, a atividade de controle exercida pelos operadores em uma indústria de processo contínuo é de suma importância para a confiabilidade desses sistemas. São esses trabalhadores que tomam as decisões finais que conduzem à parada de instalações ou a uma posição segura diante de perturbações e anomalias do sistema (DUARTE; VIDAL, 2000). O papel que exercem sobre a confiabilidade dos sistemas pode ser identificado quando adaptam os procedimentos previstos ao contexto real de trabalho, ou elaboram procedimentos originais, utilizando-se, em larga medida, de sua inteligência astuciosa (DEJOURS, 2004), para, em tempo hábil, manter o funcionamento eficiente e seguro das instalações. Este trabalho de regulação é utilizado com frequiência em sistemas complexos, conseqüência das tecnologias empregadas e da organização do trabalho. Também chega-se a esta situação por causa das relações sociais e hierárquicas de produção, que excluem os operadores e mantenedores do equipamento de uma participação efetiva nas fases de concepção e projeto de equipamentos e sistemas (SEVÁ FILHO, 2000). Destacam-se as funções dos operadores de produção e os da área de manutenção que realizam tarefas de prevenção, antecipação e recuperação dos disfuncionamentos do processo, assegurando a confiabilidade ameaçada pelas variabilidades do sistema.

Dessa forma, ao intensificar em demasia a terceirização das atividades de operação, produção e manutenção, a empresa abre espaço para a desarticu- 
lação de um segmento importante de trabalhadores. Em muitos casos, os trabalhadores demitidos são contratados por uma prestadora de serviços e, mesmo quando continuam a embarcar na mesma plataforma e a interagir com muitos de seus antigos companheiros, as regras informais construídas coletivamente ao longo do tempo podem ser desestabilizadas tal como apontaremos adiante. A despeito da capacidade de sustentação da confiabilidade pelos coletivos, entendemos que o risco introduzido ao se colocar em xeque sua coesão configurar-se-ia como mais um elemento a respaldar a necessidade de um processo de reavaliação da forma com que a terceirização foi implementada nas áreas de operação, produção e manutenção offshore. A rigor, uma reavaliação que, numa concepção mais abrangente, encarasse os fatores organizacionais e gerenciais como passíveis de se situarem na gênese de condutas que resultem em acidentes graves na indústria offshore (PATÉ CORNELL, 1993; WOOLFSON et al., 1996; FREITAS et al., 2001).

\section{Considerações metodológicas}

Nossa caixa de ferramentas teórico-metodológica tem se constituído dos materiais oriundos, principalmente, da Ergonomia da Atividade (WISNER, 1994; DANIELLOU, 2004) e da Psicodinâmica do Trabalho (DEJOURS, 1993) e, mais recentemente, também passamos a incorporar as valiosas contribuições aportadas pela abordagem ergológica. Com a incorporação desta última visamos a explorar aquilo que as abordagens precedentes oferecem enquanto possibilidade de bricolagem, ou urdidura como prefere Schwartz (2000), entre as disciplinas científicas e os saberes oriundos da atividade.

Os aportes metodológicos trazidos por tais abordagens contribuem para uma maior aproximação do trabalho real e, por conseguinte, da defasagem entre as dimensões da prescrição e do efetivamente realizado. Isto se dá em larga medida por intermédio da participação dos trabalhadores nas discussões, ao se valorizar sua experiência acumulada ao longo dos anos, seu saber-fazer, seus atributos associados àquela parcela de conhecimento que emerge no curso da atividade. Esse enfoque permite ampliar a análise das condições e relações de trabalho para além dos seus aspectos mais visíveis, ajudando-nos a acessar o que se encontra "por dentro do trabalho" (WISNER, 1987), fazendo com que nos defrontemos com alguns dos elementos que conformam sua dimensão enigmática.

Buscamos operar mobilizando uma "comunidade ampliada de pesquisa" (ATHAYDE et al., 2003) envolvendo, no momento de maior mobilização, os "pesquisadores diretos" (os dois primeiros e os dos últimos autores deste texto), o "grupo sindical" (demandante) e um "grupo de trabalhadores diretamente interessados" (contactados via direção sindical), além de um "pesqui- sador indireto" (o terceiro autor), que acompanhava a pesquisa sem participação sistemática na investigação no campo.

Foram empregadas como fontes primárias para a coleta de dados os seguintes procedimentos:

a) observações: visita à plataforma $\mathrm{P} 47$ da Petrobras (atracada no cais do porto do Rio de Janeiro); 2 visitas a aeroportos, uma em Macaé e outra em Campos (ambos no RJ), acompanhadas da realização de entrevistas abertas com trabalhadores no saguão de embarque e desembarque dos respectivos aeroportos;

b) atividades conjuntas sindicato/universidade: participação dos pesquisadores como observadores em quatro encontros da categoria, nos quais, não raro, debatiam-se aspectos associados à reestruturação produtiva e à terceirização; organização de um encontro de discussão conjunta entre os pesquisadores e os sindicalistas, na Universidade Federal Fluminense, intitulado "Ergonomia, Ergologia e Mundos do Trabalho". Este evento contou ainda com a participação de 3 pesquisadores da Universidade de Provence (França);

c) entrevistas/oficinas de trabalho:

- (13) entrevistas individuais - (09) com técnicos de atividades e qualificações diversas (operadores, plataformistas, torristas, engenheiros de perfuração de poços e de lançamento de linhas etc.), (01) com um alto gerente de RH da Petrobras na Bacia de Campos, (01) com o diretor da área de saúde e meio ambiente do Sindipetro NF, (01) com o médico do trabalho que presta serviço ao Sindipetro NF, (01) com o advogado que assessora o Sindipetro NF; e

- (20) oficinas de trabalho, caracterizadas a seguir, que funcionaram no formato de grupos de discussão. Todos os encontros citados foram registrados em fitas cassete seguindo um roteiro semi-estruturado de conversação. Portanto é importante sublinhar aqui a ênfase atribuída à dialogia, às falas, aos elementos pertinentes ao sentido ou à interpretação que as pessoas envolvidas dão à situação de trabalho.

As oficinas de trabalho (ou grupos de discussão para análise do trabalho) ocorreram sempre que possível uma vez a cada mês, desde outubro de 2002 até dezembro de 2004, na sede do sindicato, em Macaé (RJ), com duração média de 2 horas e 30 minutos para cada reunião. Funcionaram em consonância com a proposta das "comunidades ampliadas de pesquisa" indicada acima.

No período 2002-2003, os petroleiros participantes eram em sua maioria membros da direção sindical pertencentes ao quadro efetivo da Petrobras (com 10 a 25 anos de empresa). No período 2003-2004, os petroleiros que 
compuseram os grupos eram em sua maioria de empresas terceirizadas, afastados em função de acidentes ocorridos, com atuação profissional variando entre 5 e 20 anos. Os temas abordados procuraram seguir um roteiro previamente estabelecido abordando questões diversas ligadas ao trabalho destes profissionais. Em alguns momentos lançou-se mão de materiais audiovisuais que serviam para nortear a discussão em torno de um determinado tema eleito como objeto de debate minucioso.

As questões suscitadas pelos temas debatidos têm sido confrontadas com a literatura acadêmica disponível e, desta forma, o tratamento e a análise dos dados levantados nos permitem efetuar a comparação dos resultados que vêm sendo alcançados com aqueles já existentes, oriundos de pesquisas anteriores. Cabe frisar que uma parcela dos dados aqui utilizados, referentes à segunda metade dos anos 90, foi extraída da pesquisa de doutoramento do primeiro autor deste texto (FIGUEIREDO, 2001). Este estudo pode ser considerado um dos embriões do projeto de pesquisa ora em curso.

As abordagens indiretas valeram-se ainda de fontes secundárias, tais como documentos da Petrobras, de empresas subcontratadas, do sindicato, de conselhos profissionais, do ministério público e matérias de jornais. Lembramos, entretanto, que algumas das dificuldades da investigação do trabalho offshore são a limitação para a realização de observações em situação real (in loco), devido à distância das plataformas em relação a terra, além dos recorrentes entraves para a obtenção de diversas informações relevantes junto à Petrobras e suas contratadas, o que já era de se esperar em função dos acidentes de alta gravidade e repercussão envolvendo a empresa nos últimos anos.

\section{Resultados}

\subsection{Características da terceirização na Petrobras}

Levando em conta que a indústria petrolífera no Brasil sofreu um processo de intensificação da terceirização que gerou transformações expressivas no trabalho dos petroleiros, procederemos a uma breve descrição de como esse processo se desenrolou na Petrobras, o que nos ajudará a entender seu avanço no setor offshore da Bacia de Campos.

No que tange à indústria do petróleo, é importante sublinhar que a desregulamentação do setor em 1997, por intermédio da lei $\mathrm{n}^{\circ}$ 9478, quebrando o monopólio da Petrobras sobre as atividades de exploração, produção, transporte, refino, importação e exportação, contribuiu para acelerar a assimilação de tendências gerenciais adotadas por suas concorrentes multinacionais. Esta desregulamentação, funcionando como mais um elemento a pressionar e demandar a revisão do padrão gerencial anterior, impulsionou o uso da terceirização, no intuito de aumentar a produtividade da empresa, a fim de torná-la mais atrativa a investimentos e mais competitiva, a longo prazo.

No caso da Petrobras, a implantação do novo modelo de organização gerencial em 2000, que dividiu a empresa em áreas de negócio, de apoio e unidades corporativas, deu maior autonomia às subáreas quanto a questões de contratação dos serviços e fornecimento de equipamentos pelas prestadoras, corroborando o movimento de disseminação da terceirização em diversas etapas do processo produtivo. Lembramos que por trás da concepção das unidades de negócio está o maior foco em resultados em detrimento de antigas preocupações concernentes aos processos.

Além desses fatores, a não renovação do quadro de pessoal contribuiu muito para a maior contratação de terceiros. Durante a segunda metade da década de 1990 houve a suspensão dos concursos no âmbito federal, pois o governo FHC pretendia fazer um amplo levantamento dos cargos públicos existentes. A Petrobras, como empresa pública cuja única forma de ingresso ocorre via concurso, teve vedada a possibilidade de renovação de pessoal. Esse déficit de mão-obra se tornou ainda mais crítico em função do crescimento constante da produção ao longo dos anos 90. A intensificação da terceirização funcionou, então, como uma das principais medidas para surprir as lacunas nesse período de alta produção e diminuição de funcionários vinculados ao quadro de efetivos da empresa.

Atualmente, a Petrobras concentra terceirizados nos mais variados setores: da alimentação, limpeza, transporte e vigilância até cimentação e complementação de poços, perfuração e perfilagem de poços, construção de projetos, operação de sondas (DIEESE, 2004). O processo de terceirização não ocorreu somente nos chamados "serviços de apoio" ou "periféricos", como é o caso das atividades de alimentação, limpeza, transporte e vigilância, mas também nas áreas produtivas ou nas atividades-fim da empresa, naquelas inicialmente não planejadas para serem terceirizadas, tais como as atividades de operação, produção e manutenção.

Seria pertinente questionar se os ganhos pautados por esta lógica justificam não a elevação da contratação de terceiros, mas o impulso desmedido que foi dado a estas contratações, no período tomado como referência (Figura 1). Retomaremos esta indagação ao final, após a apresentação de outros dados significativos.

Tal questionamento ganha amplitude se levarmos em conta os dados apresentados por Pessanha (1994), também relacionados às variações no efetivo da Petrobras. Em se tratando da atividade offshore, ele sublinha que o número de operadores embarcados já sofria sensível 


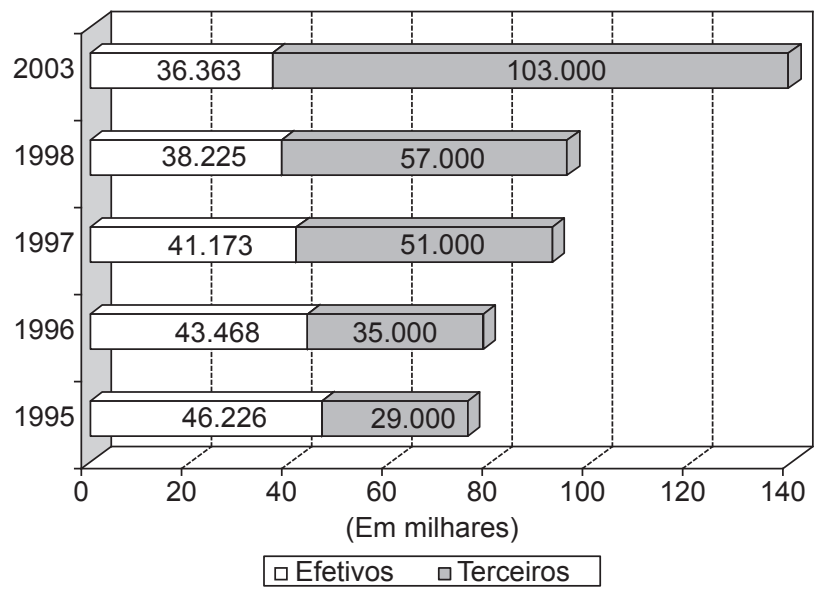

Figura 1. Número de efetivos e terceiros (1995-2003). Fonte: Jornal do Brasil (2003).

redução na virada dos anos 80/90. Ele registrou que entre 1989 e 1992 a redução foi de aproximadamente $30 \%$ nas maiores plataformas fixas. Conforme documento por ele citado, oriundo do Seminário "Tecnologia, Saúde e Meio Ambiente", realizado em maio de 1991, pelo Sindipetro-RJ, a redução de pessoal entrava em choque com o parecer emitido por engenheiros de várias plataformas, quando dos cortes efetuados no período entre 1986/87, no qual afirmavam que o número de funcionários que havia permanecido nas plataformas após os referidos cortes seria a referência para "tocá-las" dentro dos padrões de segurança.

\subsubsection{A dupla terceirização em atividades com alto grau de especialização e a antecipação da tendência à flexibilização do processo: o caso do mergulho profundo}

Embora os anos 90 registrem um avanço inegável, uma espécie de 'boom' da reestruturação produtiva na indústria petroquímica, o caso do mergulho profundo nos ajuda a visualizar o equívoco de encará-la como um processo homogêneo e concentrado. Esta atividade apresenta-se como um ótimo exemplo de um tipo de prestação de serviço que ao surgir já era executado por firmas especializadas. Neste caso, o repasse de uma determinada atividade produtiva (altamente especializada) para um terceiro dá-se na gênese da implantação desta no processo produtivo mais global, nunca tendo ficado a cargo da contratante (Petrobras). São empresas detentoras de uma tecnologia de ponta em intervenções submarinas e que atuam na Bacia de Campos desde 1972, como é o caso da Stolt Offshore (antiga Stolt Comex), antes mesmo da descoberta do primeiro poço de petróleo na região, em Garoupa (1974). Tal fato não apenas evidencia as condições propícias à terceirização que estão associadas à indústria do petróleo, e que fizemos menção anteriormente, mas, no que concerne à possibi- lidade de flexibilização do processo produtivo - um dos traços marcantes das inovações envoltas na reestruturação - antecipa tendências que ganharam vulto quando esta última se implantou de forma efetiva na petroquímica, no decorrer dos anos 90. Vejamos as características que cercam tal situação com base em Figueiredo (2001).

No decorrer dos anos 80 , pouco a pouco os sistemas de apoio às operações de mergulho profundo, instalados em plataformas e navios-sonda, foram sendo substituídos pelos modernos barcos da classe DSV (Diving Support Vessel), embarcações que davam suporte para tais intervenções, consolidando tanto uma mudança no nível da base tecnológica, como uma radical alteração de cunho organizacional, já que os DSVs deram maior flexibilidade ao atendimento das demandas dos serviços de mergulho em toda a Bacia de Campos. A desativação dos sistemas "fixos", acoplados às plataformas, gerou desemprego entre os mergulhadores, pois a partir de certo momento os sistemas de mergulho fundo restringiam-se, quase inteiramente, aos existentes nos DSVs. Os barcos passaram a desempenhar um papel similar àquele verificado em outros setores no que concerne à estratégia de externalização de serviços. No caso da construção civil, por exemplo, o concreto é produzido por uma firma terceirizada e externamente ao canteiro, chegando até este transportado pelos caminhões-betoneira. Rocha (1989), ao enfocar esta situação, chamou a atenção para a proximidade com a lógica do sistema just-in-time, e Figueiredo (1995) procurou assinalar que esta lógica se apresentava, há algum tempo, em esquemas de recrutamento de mão-de-obra no setor de construção civil.

No offshore as operações de mergulho, que sempre estiveram a cargo de empresas terceirizadas, tiveram seu suporte viabilizado por uma infra-estrutura externa às plataformas, com os navios "transportando" os serviços de mergulho até aquelas unidades. Logo, esta opção flexibilizou o trabalho dos mergulhadores, na medida em que estes passaram a atender à demanda não apenas de uma unidade (plataforma ou navio-sonda), mas de várias, de acordo com as prioridades estabelecidas.

Pode-se dizer que o mergulho profundo foi duplamente terceirizado: primeiramente, no início dessa atividade na Bacia de Campos, a Petrobras o terceirizou para as empresas especializadas, na verdade, como já frisamos, ele já nasceu nestes moldes e, posteriormente, foi "terceirizado" (a rigor, um repasse com externalização) das plataformas para os DSVs.

Esta situação também explicita que a terceirização permite à empresa contratatante transferir para as subcontratadas a gestão de uma etapa do processo que embute inúmeros e graves riscos, já que a atividade de mergulho profundo é consideradada pela OIT como uma das mais perigosas do mundo. Assim, ainda que a contratante, em nosso caso a Petrobras, seja co-responsável consta- 
tamos que o gerenciamento dos riscos de uma atividade desta natureza é assumido no cotidiano de trabalho pela subcontratada, o qual pode estar em franco descompasso com as "normas antecedentes" (SCHWARTZ, 1995) de saúde e segurança que devem nortear o desenrolar de uma atividade com tais características. É o que atestam os diversos acidentes (inclusive fatais) descritos em Figueiredo (2001).

Este quadro assume uma conformação tal que, a nosso ver, é pertinente recapitular resumidamente o debate sobre as modalidades de terceirização. Além de distinções mais nítidas entre a terceirização de atividades produtivas propriamente ditas e atividades de apoio (limpeza, vigilância, etc.), seria importante distinguir também a terceirização: i) de atividades que eram executadas pelo cliente e foram, posteriormente, repassadas a terceiros; e ii) daquelas que na instalação do processo produtivo já se encontravam a cargo das prestadoras de serviço. Isto denota uma característica estrutural de determinados setores, como o petroquímico, com a sua extensa e clássica rede de prestadores de serviços de atividades especializadas. Ainda que não adotemos denominações diferentes para as duas modalidades, verifica-se que, no segundo caso, para alguns tipos de serviço - especialmente aqueles executados por algumas das grandes empresas, citadas anteriormente (DUTRA, 1996) - a sua prestação desempenharia um papel assaz estrutural no âmbito deste setor, com remotas chances de assunção deste serviço pelo contratante. Ao contrário, no primeiro caso, as empresas contratadas desempenhariam um papel menos estrutural (por vezes conjuntural), ainda que relevante, viabilizando a retomada da execução do serviço pelo cliente, tal como vem ocorrendo, recentemente, em certos casos na bacia de Campos, a chamada "primeirização". Tais nuances nos remetem à temática da "relação de serviço" (ZARIFIAN, 2001), a ser problematizada em produções futuras.

\subsection{A terceirização e as relações de trabalho na Bacia de Campos: a precarização minando a coesão dos coletivos}

\subsubsection{A degeneração da proposta das coopera- tivas: as "coopergatos"}

Quando se fala em precarização do trabalho na Bacia de Campos, uma das situações em relevo é o processo de prestação de serviços em que, para a contratação de trabalhadores, algumas firmas terceirizadas valem-se da intermediação de cooperativas de recrutamento de mãode-obra para postos de trabalho operacionais. Estas, frequientemente chamadas de "coopergatos", funcionam em completo desacordo com a proposta que pauta o funcionamento legal das cooperativas, reproduzem o papel nocivo historicamente desempenhado pelos agenciadores de mão-de-obra em outros contextos, vulgarmente conhecidos como "gatos", Estes atuam de forma não idônea, burlando uma série de itens da legislação trabalhista. A existência dessas agenciadoras também é prática bastante antiga e difusa em outros setores da economia como, por exemplo, nos setores canavieiro e da construção civil (PAIXÃO; FIGUEIREDO, 1998).

$\mathrm{Na}$ maioria dos casos, essas empresas são criadas especificamente para concorrer em um contrato, não oferecendo garantias quanto ao pagamento de encargos trabalhistas e tendo como maior diferencial o baixíssimo preço cobrado pelo custo dos serviços prestados. A reserva dilatada de mão-de-obra, além da ênfase no menor custo como fator primordial no momento de decisão e análise da melhor proposta contratual, fizeram com que a atividade das "coopergatos" ganhasse sobrevida na Bacia de Campos.

Pelo fato de não terem capitais de reserva para o pagamento de passivos, custos administrativos e outros decorrentes da atuação de uma empresa regular e idônea, essas empresas "quebram" sistematicamente, levando a processos trabalhistas que, não raro, recaem sobre a Petrobras, que termina arcando com o ônus dos passivos devidos aos trabalhadores.

No que concerne às "coopergatos", tais problemas estão sendo postos em evidência à medida que ganha espaço a discussão em torno da precarização do trabalho terceirizado e, de acordo com Martins (2005), a Petrobras já admite evitar que seja firmado este tipo de contrato, afirmação corroborada por membros da direção sindical.

\subsubsection{As diferenças de qualificação, treinamen- to e remuneração}

Em relação à qualidade dos serviços e da mão-de-obra, uma questão recorrente ao se analisar a intensificação da terceirização refere-se à diferença de formação entre o terceirizado e o efetivo. As disparidades ficam claras quando se verifica o grau de escolaridade, por exemplo: enquanto $72,6 \%$ dos terceiros não concluíram o ensino médio, 96,2\% dos concursados (efetivos) o completaram (Martins, 2005). Além disso, as lacunas presentes no tipo de treinamento ministrado por algumas das prestadoras de serviço - usualmente em descompasso com aquele ministrado aos profissionais da Petrobras - são evidenciadas, principalmente, pela perda de qualidade nos serviços prestados. Notadamente nas atividades-fim da empresa (operação, produção e manutenção), as quais, apesar das inúmeras críticas já desferidas, que vão desde contrariar o princípio da focalização até transferir a responsabilidade de gestão, também foram alvo do processo de terceirização.

Um outro ponto recorrente na visão da população pesquisada, que merece atenção especial por parte da gerência na Bacia de Campos, é a atuação de diversos 
profissionais terceirizados, sobretudo novatos, cuja formação encontra-se aquém das competências requeridas pelas tarefas a serem executadas. Um problema também para os novatos efetivos, os "genéricos", que, na fala de diversos petroleiros, "custam menos e deveriam produzir o mesmo efeito", pois constata-se que há um componente da formação que requer uma experiência que só se absorve ao longo do tempo, ou seja, o acesso a um dado repertório de condutas demanda uma extensa e contínua interação com o cotidiano de trabalho no curso da atividade, requisito indispensável para a apreensão dos elementos que compõem o "gênero profissional" (CLOT; FAÏTA, 2000). Por outro lado, mesmo entre os efetivos é consenso que a postura gerencial em focar mais os resultados deixou em segundo plano fatores associados à regularidade do processo e à segurança das operações. Com o passar do tempo tais fatores contribuíram de distintas maneiras para o aumento do número de acidentes e suas conseqüências nefastas. Os efetivos, que deveriam espelhar aos terceiros condutas seguras de atuação terminam, por vezes, disseminando uma conduta de não priorização da segurança, premidos entre os determinantes da prescrição e as injunções da dominação, e remetendo-nos ao incontonável registro da situação de trabalho como "debate de normas" (SCHWARTZ, 2000).

Um outro aspecto importante refere-se à diferença de remuneração e benefícios. Esta se traduz na diferença em relação ao salário e benefícios conseguidos por meio dos acordos coletivos. Na média o efetivo possui remuneração superior ao terceiro, não raro chegando ao dobro, embora em certos casos isto não ocorra, verificando-se até mesmo o contrário, em função de alguns terceirizados deterem uma elevada qualificação para a execução de tarefas altamente especializadas, exercidas por um grupo seleto.

Quanto aos benefícios, 80,6\% dos terceiros não têm plano de saúde, e enquanto os efetivos ganham salário completo durante as férias, os terceiros ganham um terço do salário, que corresponde ao mínimo previsto por lei (A TERCEIRIZAÇÃO..., 2003). Além dessas diferenças, em especial na Bacia de Campos, há um número menor de dias defolgaonshore, uma vezque os trabalhadores efetivos da Petrobras embarcam durante 14 dias e descansam 21 dias (regime $14 \times 21$ ). Para os terceirizados essa relação é $14 \times 14$, deixando-os mais vulneráveis aos riscos do trabalho em turnos no offshore (RODRIGUES, 2001).

A diferença quanto aos benefícios e remuneração é mais um dentre os indicadores que sinalizam a tendência à precarização do trabalho. Na questão da qualificação, também aqui se mostra o elemento principal para estabelecer-se uma divisão entre os terceiros "precarizados" e os "privilegiados". Os primeiros, em maior número, são os que sentem mais diretamente os efeitos do desequilíbrio entre os benefícios, pois para os "privilegiados" o pagamento concedido pode incluir um plano de previdência privada e outros benefícios conferidos ao efetivo. No caso do segundo grupo, há um núcleo cuja qualificação é extremamente valorizada no mercado, compondo, assim, aquilo que poderíamos chamar de "aristocracia terceirizada".

\subsubsection{Os acidentes e as subnotificações: a precarização insidiosa}

Vários relatos sinalizam que inúmeros casos de acidentes graves com terceiros não são devidamente notificados. São registrados como doença e não acidente, ou então computados com enorme atraso. Se tal procedimento se verifica nas notificações de acidentes com efetivos, no caso de terceiros isto se acentua. As subnotificações têm reverberado de forma negativa na credibilidade das Comunicações de Acidente de Trabalho (CATs) como instrumento de registro de acidentes. Tal descrédito dado às informações nelas contidas impede uma mensuração mais eficaz acerca do número e do tipo de acidentes que mais ocorrem com os terceirizados.

Para se entender a recorrência deste tipo de subterfúgio (a subnotificação), é importante ter em mira alguns indicadores de acidente na Petrobras e na Bacia de Campos nos últimos dez anos. Dados da Federação Única dos Petroleiros (FUP) mostram que das 133 mortes por acidentes de trabalho em toda a Petrobras, entre 19982003, 102 foram com trabalhadores terceirizados, ou seja, 76\%. Tal índice corresponde aproximadamente ao percentual dessa categoria na empresa, engendrando uma falsa idéia de proporcionalidade entre número de terceirizados e de acidentes, quando, na verdade, sabe-se que a subnotificação de acidentes é bem superior entre os terceiros, como indicou nossa experiência na Bacia de Campos. Vale destacar que a tendência à subnotificação de acidentes, no caso da região estudada, também termina sendo estimulada pela estratégia de premiação (via pagamento de um bônus) das unidades que ostentam os melhores indicadores - em que a melhor situação é a ausência de acidentes - ocasionando dificuldades em se mensurar a real dimensão do problema, inclusive daqueles eventos que resultam em afastamento.

Além da premiação mencionada acima, no que tange ao processo de avaliação por desempenho gerencial, um outro fator que também deve ser realçado diz respeito a algumas das metas de produção estarem em descompasso com as metas referentes à segurança nas operações. Se na remuneração a importância dada à segurança fica em segundo plano, acentua-se a permanência de atitudes gerenciais com ênfase na produção em detrimento da prevenção de acidentes. 
Com relação aos dados apurados junto ao SindipetroNF, referentes ao período 1998-2002 na Bacia de Campos, temos 133 acidentes com afastamento sendo 54 fatais. A Figura 2 a seguir mostra as ocorrências ano a ano, no decorrer do período em questão, indicando um número maior de óbitos envolvendo trabalhadores terceirizados.

Em relação ao número maior de óbitos da Petrobras (de efetivos) no ano de 2001, que contestaria nossa afirmação anterior, vale relembrar que 2001 foi o ano do acidente com a plataforma P-36, que ocasionou a morte de 11 funcionários brigadistas da Petrobras e o naufrágio seguido de perda total da embarcação. Por sinal, este terrível acidente pode ser visto como o ápice de um processo em que a sucessão dos eventos precedentes denotava uma substancial e perigosa defasagem entre a gestão da inovação tecnológioca e a gestão do risco. A Figura 2 indica que o número de acidentes seguia uma rota ascendente ao final da década passada. Nos meses que antecederam o trágico episódio, ocorrido em 15/03/01, somente naquele ano, ocorreram 4 mortes: duas delas por inalação de gás sulfídrico na P-37, uma em conseqüência de queimaduras na PNA1 e uma outra em que um trabalhador, a bordo do rebocador 'Provider', foi lançado ao mar e não teve seu corpo localizado. $\mathrm{O}$ quadro não era preocupante apenas no norte fluminense, assim o atestam os dois grandes vazamentos de óleo no ano de 2000 - na baía de Guanabara (RJ) e no Rio Iguaçu (PR) - e um outro vazamento em 2001, no terminal de Alemoa (SP).

Ainda sobre o offshore fluminense não custa lembrar que mesmo após o desastre com a plataforma P-36 os acidentes fatais continuaram a ocorrer, acometendo, principalmente, os trabalhadores terceirizados das prestadoras de serviço da Petrobras em inúmeras áreas. Apesar da queda no número de acidentes em 2002 (cf. Figura 2), o quase desastre com a P-34 naquele ano, com 25 homens atirando-se ao mar e sérias avarias na unidade, por pouco não se consumou num outro gravíssimo acidente ampliado. Recordemos ainda que em julho de 2003 mais 5 trabalhadores morreram devido à queda

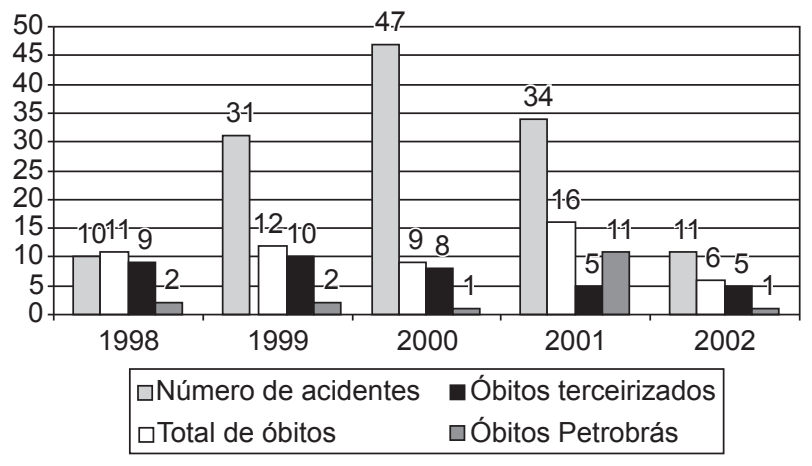

Figura 2. Número de acidentes (1998-2002). Fonte: Departamento de Saúde, Meio Ambiente e Tecnologia do Sindipetro NF. de uma aeronave e, cerca de um ano depois, em julho de 2004, tivemos mais um episódio trágico, também em conseqüência da queda de um helicóptero que vitimou 6 funcionários, engrossando a incômoda estatística de mortes por acidentes de trabalho verificados na Bacia de Campos, malgrado os esforços que a empresa alega estar fazendo para reverter esta tendência, e que tais episódios demonstram ser insuficientes. Além disso, podemos retroceder novamente e sublinhar que, em abril de 1997, após a morte de um mergulhador a $297 \mathrm{~m}$ de profundidade, a Assembléia Legislativa do RJ instaurou uma Comissão Parlamentar de Inquérito (CPI) para investigar a questão da segurança e condições de trabalho no offshore fluminense (FIGUEIREDO, 2001), proposta que voltou a ser encaminhada sem ser efetivada após o desastre da P-36. Frente aos dados aqui apresentados não resta dúvida que a situação dos terceirizados atingiu um patamar crítico.

\section{Conclusão}

Buscando melhor sintetizar e destacar nossas principais contribuições ao debate suscitado pela temática norteadora do presente artigo, e tomando por base os resultados apresentados anteriormente, optamos por subdividir a conclusão, em tópicos, da seguinte forma:

a) Constatamos que com o avanço da terceirização as atividades que, em sua maioria, ficavam a cargo dos efetivos da Petrobras foram sendo cada vez mais repassadas a trabalhadores de diversas prestadoras de serviço e a trabalhadores autônomos, em alguns casos com sensíveis diferenças nos padrões de treinamento e de remuneração. A elevada rotatividade nas plataformas, tanto da gerência quanto dos trabalhadores, aliada à pouca renovação de pessoal efetivo, levaram, ao longo do tempo, à perda de parte do potencial auferido pelo entrosamento adquirido por algumas equipes. Este entrosamento passa pela constituição de regras que extrapolam o estatuto formal da organização do trabalho, lastreada por uma espécie de acordo tácito entre os trabalhadores que, para se estabelecer, requer tempo de maturação e confiança. Como a elevada rotatividade coloca em xeque este compromisso, estaria assim contribuindo para a desestabilização destas regras e aquilo que estas podem agregar de positivo à confiabilidade do sistema. Com efeito, este potencial é algo que pode funcionar como um verdadeiro ardil na gestão de situações incidentais e acidentais (LLORY, 1999; DEJOURS, 2004), em que se necessita de tomadas de decisão extremamente rápidas. Aqui, o conhecimento mútuo (PAVARD; DECORTIS, 1994) das competências em jogo - inclusive o conhecimento daquilo que seja identificado como incompletude faz toda a diferença. Julgamos procedente afirmar que 
os efeitos da reestruturação nos coletivos de trabalho offshore, via flexibilização das relações de trabalho, aqui manifesta na maior rotatividade entre postos e aumento da terceirização, tem propiciado a fragmentação destes coletivos, comprometendo, tal como frisamos acima, aquilo que estes teriam de positivo e crucial a agregar para a confiabilidade do sistema. Estas possíveis perdas no ativo de conhecimento (um patrimônio longamente acumulado), até onde pudemos perceber, não foram devidamente avaliadas ao se optar pela terceirização, enquanto instrumento de gestão, da forma com que esta foi conduzida até recentemente. Adotam-se medidas que trazem implicações sérias para o trabalho passando-se ao largo do "ponto de vista da atividade" (HUBAULT, 2004);

b) Seria pertinente retomar o questionamento acerca dos ganhos pautados por esta lógica. Até que ponto eles justificariam, para além da elevação da contratação de terceiros, o impulso desmedido que foi dado a estas contratações, no período tomado como referência na Figura 1. Isto porque sabemos que os efeitos da terceirização tidos como positivos são, ao menos parcialmente, contrabalançados por algumas consequiências nefastas a longo prazo, tal como atestam alguns de nossos resultados apresentados no tópico anterior: a elevação do índice de acidentes (cf. Figura 2) e os prejuízos que estes acarretam para a imagem da empresa, que busca ampliar sua inserção no mercado internacional; os custos relacionados ao aumento de processos trabalhistas; a maior sobrecarga sobre alguns dos efetivos e o componente de risco que esta introduz; etc. Logo, questionamos até que ponto o peso de tais fatores (alguns deles pouco tangíveis) teria sido criteriosamente levado em conta ao se tomar a decisão estratégica não somente de terceirizar algumas das atividades-meio, mas de repassar a prestadores algumas das atividades-fim, e alterar drasticamente a proporção entre efetivos e terceirizados como demonstram os dados da Figura 1;

c) Esta problematização ganha contornos mais evidentes ao consultarmos o documento intitulado "Diagnóstico da Terceirização na Petrobras", elaborado em 2001 por um grupo constituído no mesmo ano, após o acidente com a plataforma P-36, e integrado por gerentes e profissionais vinculados aos diferentes segmentos do sistema Petrobras. A este grupo foi designada a função de: estabelecer um diagnóstico sobre o estágio da terceirização na Petrobras; propor um modelo para caracterização de contratos de prestação de serviços; e apresentar recomendações visando a melhorias no processo de terceirização na empresa.

[...] o pessoal das contratadas não está integrado às atividades da Petrobras, criando interfaces desnecessárias e trazendo um impacto negativo sobre a produtividade e o SMS (Programa de Segurança, Meio Ambiente e Saúde). (PETROBRAS, 2001, p. 49, grifo nosso).

d) Julgamos oportuno fazer menção a este documento para salientar, em primeiro lugar, a importância de não se estabelecer uma correlação muito apressada entre a intensificação da terceirização e o aumento da produtividade, que se configura numa das principais justificativas para levar-se a cabo a terceirização nos moldes em que esta estratégia foi implementada. Em segundo lugar, para chamar a atenção sobre as influências negativas desta mesma lógica na esfera da saúde e segurança;

e) A análise da terceirização levando em conta a sua importância no desenvolvimento da indústria petroquímica offshore, sua intensificação ocorrida durante a última década e, principalmente, seus efeitos negativos no tocante às relações de trabalho, à saúde e segurança e à qualidade suscitaram uma série de ressalvas a respeito do modelo adotado, engendrando condições para que uma revisão fosse empreendida no período recente. Não por acaso a Petrobras estaria iniciando a implementação do processo de "primeirização" de algumas das atividades que tinham sido terceirizadas e que, gradualmente, estariam retornando às mãos dos efetivos da empresa; e

f) Tais injunções nos permitiriam asseverar que não se está considerando as implicações decorrentes de tal postura (intensificação da terceirização) com o rigor e a amplitude que estas exigem, requisito indispensável ao se analisar essa prática e suas relações com o trabalho na indústria petroquímica, em especial no setor offshore. Em suma, a lógica que foi se constituindo propiciou o avanço da desregulação do trabalho respaldada pela predominância, em âmbito nacional, de um discurso empresarial condenatório aos mecanismos de regulação trabalhista existentes, que se mostrariam inadequados e onerosos tanto para as empresas como para os empregados. Assim, a flexibilização das relações de trabalho no setor offshore encontrou condições favoráveis para se difundir e reproduzir a tendência à precarização verificada em outros setores, sempre guardadas as peculiaridades que marcam o avanço de tais processos quando levamos em conta as distinções entre seus respectivos contextos. 


\title{
Productive reorganization, outsourcing and labor relations in an offshore oil industry in Campos Basin
}

\begin{abstract}
This paper analyses the correlations between the intensive use of outsourcing and labor organizations on offshore oil platforms in the Campos Basin (Rio de Janeiro). We studied and followed the reported empirical field over the last 10 years in a systematic way. The theorist-methodological referential applied in our research, in which this work can be found, was inspired by Ergonomics of the Activity and the Psycho Dynamic of the Work. In our analysis, two aspects should be mentioned: the tendency of increasing precariousness in a global sense and the possible waste offormal and informal knowledge due to labor collective fraction when we consider the cohesion of this collective as an important element for system reliability. In fact, the increased precariousness of the work contributes to this fraction, and one of the main reasons is the outsourcing criteria which has not advanced much, because of various initiatives of flexible organization connected to restructuring the production sector. This situation has brought consequences to workers' health and safety, suggesting that the outsourcing option as a labor management tool, in a way in which it has been done recently, would not been considered as being severe in terms of the implications.
\end{abstract}

Keywords: Outsourcing. Productive reorganization. Offshore oil industry. Complex social-technical systems. Labor relations. Health and safety.

\section{Referências bibliográficas}

A TERCEIRIZAÇÃO que Mata. O Globo, Rio de Janeiro. Série de reportagens veiculada de 20 a 27 de julho de 2003 e que retrata a maior periculosidade do trabalho realizado por terceiros. 2003.

ARAÚJO, A. Paradoxos da modernização: terceirização e segurança em uma refinaria de petróleo. 2001. Tese (Doutorado em Saúde Coletiva) - ENSP, Fundação Oswaldo Cruz, Rio de Janeiro, 2001.

ATHAYDE, M; BRITO, J.; NEVES, M. (orgs.). Caderno de textos: programa de formação em saúde, gênero e trabalho nas escolas. João Pessoa: Editora Universitária/UFPB, 2003.

CASTELLS, M. La economia informacional, la nueva division del trabajo y el proyecto socialista. Revista Socialismo del Futuro, Madri, n. 4, p. 73-89, 1991.

CHESNAIS, F. (org.). A finança mundializada: raízes sociais e políticas, configurações e conseqüências. São Paulo: Boitempo, 2005.

CLOT, Y; FAÏTA, D. Genres et styles en analyse du travail. Concept et méthodes. Revue Intenationale de Psychopathologie et de Psychodynamique du Travail, Paris, n. 4, p. 7-42, 2000.

DANIELLOU, F. Le statut de la pratique et des connaissances dans l'intervention ergonomique de conception. 1992. Tese (Document de synthèse), Université de Toulouse-Le Mirail, Toulouse, 1992.

DANIELLOU, F. Introdução: Questões epistemológicas acerca da ergonomia. In: DANIELLOU, F. (org.). A ergonomia em busca de seus princípios. São Paulo: Edgard Blücher, 2004. p. 1-13.

DEJOURS, C. Travail: usure mentale: de la psychopathologie à la psychodynamique du travail. Nouvelle édition augmentée. Paris: Bayard, 1993.

DEJOURS, C. O fator humano. Rio de Janeiro: Editora da Fundação Getúlio Vargas, 1997.

DEJOURS, C. In: LANCMAN, S.; SZNELWAR, L. (orgs.). Christophe Dejours: da psicopatologia à psicodinâmica do trabalho. Rio de Janeiro: Editora Fiocruz, Brasília: Paralelo 15, 2004.

DIEESE. Departamento Intersindical de Estatísticas e Estudos Sócio-Econômicos. A Terceirização na Petrobras: Alguns pontos para reflexão. Rio de Janeiro: SS, Dieese, FUP, 2004.

DRUCK, M. Terceirização: (des)fordizando a fábrica - Um estudo do complexo petroquímico da Bahia. São Paulo: Boitempo, 1999.

DUARTE, F. A análise ergonômica e a determinação de efetivos: estudo da modernização tecnológica de uma refinaria de petróleo no Brasil. 1994. Tese (Doutorado em Engenharia de Produção) - Curso de Pós-Graduação em Engenharia de Produção, COPPE, Universidade Federal do Rio de Janeiro, Rio de Janeiro, 1994.

DUARTE, F.; VIDAL, M. Uma abordagem ergonômica da confiabilidade e a noção de modo degradado de funcionamento. In: FREITAS, C.; PORTO, M., MACHADO, J. (orgs.). Acidentes industriais ampliados: desafios e perspectivas para o controle e a prevenção. Rio de Janeiro: Editora Fiocruz, 2000. p. 83-105.

DUTRA, L. Por uma história alternativa do petróleo. In: FREITAS, M.; DUTRA, L. (eds.). Pesquisas recentes em energia, meio ambiente e tecnologia. Rio de Janeiro: COPPE/UFRJ, 1996. p. 91-114.

DUTRA, L; CECCHI, J. Petróleo, preços e tributos: experiência internacional e política energética nacional. Rio de Janeiro: Tama, 1998.

FERREIRA, L; IGUTI, A. O trabalho dos petroleiros: perigoso, complexo, contínuo e coletivo. São Paulo: Scritta, 1996.

FIGUEIREDO, M. O trabalho em tubulões a ar comprimido: nos subterrâneos da Linha Vermelha. 1995. Dissertação (Mestrado em Engenharia de Produção) - Curso de Pós-graduação em Engenharia de Produção, COPPE, Universidade Federal do Rio de Janeiro, Rio de Janeiro, 1995. 
FIGUEIREDO, M. O trabalho de mergulho profundo em instalações petrolíferas offshore na Bacia de Campos: confiabilidade e segurança em meio à guerra de 'Highlander' contra Leviatã. 2001. Tese (Doutorado em Engenharia de Produção) - Curso de Pós-graduação em Engenharia de Produção, COPPE, Universidade Federal do Rio de Janeiro, Rio de Janeiro, 2001.

FIGUEIREDO, M.; ATHAYDE, M. Coletivos de trabalho e componentes subjetivos da confiabilidade em sistemas sociotécnicos complexos: considerações a partir da situação de trabalho em mergulho profundo na Bacia de Campos/RJ. In: FIGUEIREDO, M.; ATHAYDE, M.; BRITO, Jussara; ALVAREZ, D. (orgs.). Labirintos do Trabalho: interrogações e olhares sobre o trabalho vivo. Rio de Janeiro: DP\&A, 2004.

FIGUEIREDO, M. et al. Dossiê: Trabalho, saúde e segurança na indústria petrolífera offshore da bacia de Campos. Niterói, 2004. (Apresentado ao Sindicato dos Petroleiros do Norte Fluminense).

FREITAS, C. et al. Acidentes de trabalho em plataformas de petróleo da Bacia de Campos. Cadernos de Saúde Pública, Rio de Janeiro, v. 17, n. 1, p. 117-130, 2001.

HARVEY, D. A condição pós-moderna: uma pesquisa sobre as origens da mudança cultural. São Paulo: Loyola, 1992.

HUBAULT, F. Do que a ergonomia pode fazer a análise? In: DANIELLOU, F. (org.). A ergonomia em busca de seus princípios: debates epistemológicos. São Paulo: Edgard Blücher, 2004.

LAZZARATO, M.; NEGRI, A. Trabalho imaterial: formas de vida e produção de subjetividade. Rio de Janeiro: DP\&A, 2001.

LEPLAT, J.; TERSSAC, G. Les facteurs humains de la fiabilité dans le systèmes complexes. Toulouse: Octarès Éditions, 1990.

LLORY, M. Acidentes industriais: O custo do silêncio. Rio de Janeiro: MultiMais Editorial, 1999.

MACHADO, J.; PORTO, M., FREITAS, C. Perspectivas para uma Análise Interdisciplinar e Participativa de Acidentes (Aipa) no Contexto da Indústria de Processo. In: FREITAS, C., PORTO, M., MACHADO, J. (orgs.). Acidentes industriais ampliados: desafios e perspectivas para o controle e a prevenção, Rio de Janeiro: Editora Fiocruz, 2000. cap. 1.

MARTINS, L. Diagnóstico da terceirização e sua relação com as áreas de saúde, meio ambiente e segurança na indústria petrolífera offshore na Bacia de Campos. 2005. Dissertação (Mestrado em Engenharia de Produção) - Curso de Pósgraduação em Engenharia de Produção, Escola de Engenharia, Universidade Federal Fluminense, Niterói, 2005.

PAIXÃO, M.; FIGUEIREDO, M. A Vanguarda do Atraso: Os Riscos da Precarização do Trabalho no Brasil. Revista Proposta, Rio de Janeiro, FASE, n. 75, p. 6-23, 1998.

PATÉ-CORNELL, E. Learning from the Piper Alpha Accident: a postmortem analysis of technical and organizational factors. Risk Analysis, v. 13, n. 2, p. 215-232, 1993.
PAVARD, B.; DECORTIS, F. Communication et coopération: de la théorie des actes de langage à l'approche ethnométhodologique. In: PAVARD, B, Systèmes coopératifs: de la modélisation à la conception. Toulouse: Octarès Éditions, 1994. p. 21-50.

PERROW, C. Normal Accidents: living with high-risk technologies. New York: Basic Book, 1984.

PESSANHA, R. O trabalho offshore: inovação tecnológica, organização do trabalho e qualificação do operador de produção na Bacia de Campos. 1994. Dissertação (Mestrado em Engenharia de Produção) - Curso de Pós-graduação em Engenharia de Produção, COPPE, Universidade Federal do Rio de Janeiro, Rio de Janeiro, 1994.

PETROBRAS. Diagnóstico da Terceirização na Petrobras. Rio de Janeiro, 2001.

ROCHA, M. Uma tendência industrializante no processo edificativo: a externalização dos serviços. 1989. Dissertação (Mestrado em Engenharia de Produção) - Curso de Pósgraduação em Engenharia de Produção, COPPE, Universidade Federal do Rio de Janeiro, Rio de Janeiro, 1989.

RODRIGUES, V. O trabalho offshore em unidades de perfuração marítima com ênfase no trabalho em turnos. 2001. Dissertação (Mestrado em Engenharia de Produção) - Curso de Pós-graduação em Engenharia de Produção, Universidade Federal de Alfenas, Alfenas, 2001.

SCHWARTZ, Y. "De l'inconfort intellectuel, ou: comment penser les activités humaines?". Revue La liberté du travail - Éditions Syllepse, Paris, p. 99-149, 1995.

SCHWARTZ, Y. Le paradigme ergologique ou um métier de philosophe. Toulouse: Octarès Éditions, 2000.

SEVÁ FILHO, O. Riscos técnicos coletivos e desorganização do trabalho: alarmes e emergências na indústria petrolífera brasileira em seu transe de mundialização. 1997. Relatório de pesquisa (Pós-doutorado em Engenharia de Produção) Curso de Pós-graduação em Engenharia de Produção, COPPE, Universidade Federal do Rio de Janeiro, Rio de Janeiro.

SEVÁ FILHO, O. Seguuura, peão! Alertas sobre o risco técnico coletivo crescente na indústria petrolífera. In: FREITAS, C.; PORTO, M.; MACHADO, J. (orgs.). Acidentes industriais ampliados: desafios e perspectivas para o controle e a prevenção. Rio de Janeiro: Editora FIOCRUZ, 2000. Cap.6.

TORRES FILHO, E. O papel do petróleo na geopolítica americana. In: FIORI, J. (orgs.). O poder americano. Petrópolis: Vozes, 2004. p. 309-346.

WISNER, A. Por dentro do trabalho: ergonomia: método \& técnica. São Paulo: FTD-Oboré, 1987.

WISNER, A. A inteligência no trabalho: textos selecionados de ergonomia. São Paulo: Fundacentro, 1994

WOOLFSON, C; FOSTER, John; BECK, Mathias. Paying For the Piper: Capital and Labour in Britain's Offshore Oil Industry. London: Mansell, 1996.

ZARIFIAN, P. Mutação dos sistemas produtivos e competências profissionais: a produção industrial de serviço. In: SALERNO, M. (org.). Relação de serviço: produção e avaliação. São Paulo: Editora Senac, 2001. p. 67-93. 


\section{Sobre os autores}

\section{Denise Alvarez}

José Diego Suarez

\section{Renata Pereira}

Mestrado em Engenharia de Produção da UFF, Núcleo de Estudos em Inovação, Conhecimento e Trabalho - NEICT, Rua Passo da Pátria, 156, CEP 24210-240,São Domingos, Niterói, RJ, Brasil,

e-mail: denisealvarez@ neict.uff.br, diegorj@gmail.com, remirandapp@gmail.com.br

\section{Marcelo Figueiredo}

Mestrado em Engenharia de Produção da UFF, Núcleo de Estudos em Inovação, Conhecimento e Trabalho - NEICT, Rua Passo da Pátria, 156, CEP 24210-240, São Domingos, Niterói, RJ, Brasil

Fundação Carlos Chagas Filho de Amparo à Pesquisa do Estado do Rio de Janeiro - Faperj, e-mail: marceloparada@uol.com.br

\section{Milton Athayde}

Programa de Pós-Graduação em Psicologia Social, Instituto de Psicologia da UERJ, Rua São $F^{\mathrm{co}}$ Xavier, 5 - 10 andar, CEP 20000-000 Maracanã, Rio de Janeiro, RJ, Brasil e-mail: miltonathayde@uol.com.br

Agradecimentos: Aos trabalhadores petroleiros, que se dispuseram a ajudar na difícil tarefa de composição da nossa comunidade ampliada de pesquisa. Neste esforço o Sindipetro NF (Sindicato dos Petroleiros do Norte Fluminense) também assumiu uma relevante contribuição, a qual nos vem sendo dada ao longo de toda a investigação. Cabe ainda agradecermos à Fundação Carlos Chagas Filho de Amparo à Pesquisa do Estado do Rio de Janeiro (Faperj), pois à época do envio do artigo o professor Marcelo Figueiredo era bolsista de pós-doutorado deste órgão, sob a orientação do professor Milton Athayde, junto ao Programa de Pós-Graduação de Psicologia Social (PPGPS/UERJ).

Recebido em 27/10/2005 Aceito em 10/11/2006 